\title{
Genealogical branches
}

I. The family of Great-Grandfather Richard Edgeworth xxv

II. The families of Grandfather Richard Lovell Edgeworth xxvi

III. The family of Great-Grandfather Daniel Augustus

\section{Beaufort $\quad$ xxx}

IV. The family of Uncle M. Pakenham Edgeworth xxxi

V. The family of Great-Grandfather Tirs Eroles i Magallit xxxii

VI. The family of Great-Grandfather Sebastià Eroles i Turbiàs ('Marquet')

xxxiii

VII. The family of Grandfather Anton Eroles i Sancho xxxiv

VIII. The family of Francis Beaufort Edgeworth xxxv 